\title{
Phytochemicals as Antiviral Agents: Recent Updates
}

\author{
Ritu Ghildiyal, Vijeta Prakash, V. K. Chaudhary, \\ Vandana Gupta, and Reema Gabrani
}

\section{Introduction}

The distressing threat of viral diseases to human beings raises a serious concern worldwide. New viral diseases have been reported continuously with severe health issues, and the lack of effective antiviral treatment makes them more severe (Kapoor et al. 2017). Most of the viral diseases like influenza, HIV, and chikungunya and other diseases caused by alphaviruses and flaviviruses are emerging with the great risk. More recently, Coronavirus disease (COVID-19) caused by a newly identified coronavirus has become pandemic, and affected world's population severely. Nowadays, the development of effective treatment and antivirals against virus has become difficult, due to the ability of viruses to mutate their genome and become resistant to drugs (Irwin et al. 2016). Moreover, the antiviral drugs also exhibit adverse side effects, which directly and indirectly affect the human health. This leads towards the development of plant-based drugs and herbal treatments with minimal side effects (Biswas et al. 2019). Human depends on the traditional plants to fulfill their basic necessities. Plant-based anti-infection treatments are attracting the focus of modern world healthcare researchers, because of the minimal side effects with effective health benefits. Over the past few years, plant-based drug discovery has been continuously evaluated for its antibacterial, antiviral, anticancerous, and

\footnotetext{
R. Ghildiyal · V. Prakash $\cdot$ R. Gabrani $(\bowtie)$

Center for Emerging Diseases, Department of Biotechnology, Jaypee Institute of Information Technology, Noida, Uttar Pradesh, India

e-mail: reema.gabrani@jiit.ac.in

V. K. Chaudhary

Centre for Innovation in Infectious Disease Research, Education and Training, University of Delhi South Campus, New Delhi, India

V. Gupta

Department of Microbiology, Ram Lal Anand College, University of Delhi South Campus (UDSC), New Delhi, India
} 
antioxidant activities (Biswas et al. 2019; Lillehoj et al. 2018). Moreover, the antiviral activities of plant-based compounds have been evaluated for emerging viral diseases. Plant-based antiviral natural compounds are the most suitable and best alternative of antiviral medicines/inhibitors/drugs, because of less toxicity (Lillehoj et al. 2018). Plant-based potential bioactive compounds, having antiviral properties have been proved superior, and could be combined with the preexisting therapies, along with the different delivery methods to enhance the effectiveness of antiviral along with good bioavailability (Kapoor et al. 2017).

Viruses possess DNA or RNA genome with protein envelops, and depend on the host metabolism and environment to replicate and survive. They exploit the cellular machinery of host and disseminate throughout the body (Helenius 2018). Viruses have the ability to invade and adopt evasion strategies, which is an important challenge during the development of antivirals. Since the plants have metabolites/chemicals with variety of properties, they could be evaluated and used to counter the evasion and drug-resistance difficulties related with the antivirals, and thus will inhibit the viral dissemination (Irwin et al. 2016). There are several mechanisms, which govern the antiviral activity of phytochemicals. For instance, few of the antiviral phytochemicals, which bind to carbohydrate moiety tend to target the cell entry (Idris et al. 2016). This approach limits the viral penetration, resists its coating, and eventually inhibits the growth of viruses. Additionally, some of the compounds directly inhibit viral replication and hence prevent its propagation (Kapoor et al. 2017). Herein, we will focus on the plant-based antivirals reported to inhibit viral replication and the mode of their action.

\section{$2 \quad$ Plant-Based Antiviral Molecules}

Nowadays, research and development programs are continuously adopting approaches based on plant-based products for the development of drugs. Pure compounds and plant extracts have been investigated for the synthesis of new pharmaceuticals and therapeutics (Oliveira et al. 2017). Plants have a variety of secondary metabolites like flavonoids, terpenoids, lignans, tannins, and alkaloids having diverse anti-infection activities, as well as antioxidant activities (Kapoor et al. 2017; Akram et al. 2018). There are several classes of phytochemicals, which are used as antivirals (Fig. 1) (Rex et al. 2018; Younas et al. 2018). These include phenolics, carotenoids, terpenoids, and alkaloids. Out of which, the phytochemicals belonging to phenolics, alkaloids, and terpenoids have been explained in further sections (Kapoor et al. 2017). The family of phenolics contains various subclasses, such as phenolic acids, flavonoids, stilbenes, coumarins, and tannins. Several studies of phytochemicals exhibiting antiviral properties have been reported targeting viruses like dengue virus, hepatitis virus, rotavirus, chikungunya virus, Japanese encephalitis virus, herpes virus, Zika virus, influenza virus, human immunodeficiency virus (HIV), and human papilloma virus (Table 1) (Oliveira et al. 2017; Akram et al. 2018). These viruses have either DNA or RNA as genetic material. Thus, phytochemicals exhibit different mode of action against any infection or disease (Perera and Efferth 2012). Some of the phytochemicals and their mode of actions are discussed in details. 


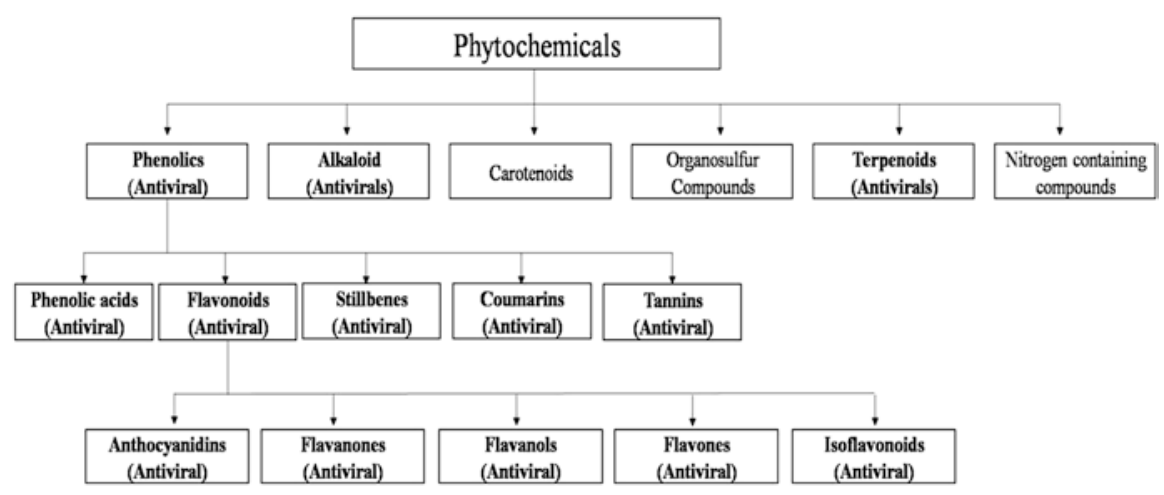

Fig. 1 Classification of phytochemicals used as antivirals (in bold)

Various strategies have been adopted to control viral infection. Viral attachment can be inhibited by either blocking the viral binding sites or host receptors. Virus can be inhibited at various stages of its infection (Fig. 2) (Subudhi et al. 2018). Some of the strategies directly inhibit the viral replication by targeting DNA/RNA polymerase, posttranslation modification of viral proteins, or viral assembly (Subudhi et al. 2018). Several mechanisms have been adopted by phytochemicals to inhibit viral replication. For instance, epigallocatechin gallate (EGCG) inactivates the host enzyme or viral enzyme which promotes the growth of the virus, such as RNA polymerase, protease, and reverse transcriptase (Lipson et al. 2017). Another mechanism adopted by flavonoids is to inhibit phosphorylation of protein, which restricts the replication of HIV (Ahmad et al. 2015). The inhibition of various viruses, such as influenza virus, HIV, and herpes simplex virus (HSV) was achieved at the stage of viral RNA synthesis (Kumar and Pandey 2013).

\subsection{Flavonoids as Antiviral Agents}

Flavonoids are polyphenolic secondary compounds of plants with several properties, such as anticancerous, antimicrobial, and antiviral. Flavonoids are widely present in many fruits, seeds, and vegetables as a result of abiotic stress (Carletti et al. 2014; Zakaryan et al. 2017). Flavonoids are being constantly researched upon for antiviral activities (Jacob and Thomas 2019). EGCG is one of the flavonoids, and is an important component of green tea. It has been reported to have antiviral activity against rotavirus strain SA-11 (Lipson et al. 2017). Zakaryan et al. reported baicalein, another flavonoid (flavone), having antiviral activity against human cytomegalovirus (HCMV). Baicalein is also reported for the inhibition of different stages of the replication of dengue virus. Fisetin and quercetagetin fall under the category of flavonols, and are exploited for their antiviral activities (Zakaryan et al. 2017). Fisetin was successfully reported to inhibit the replication of dengue virus and enterovirus A71 in vitro (Min et al. 2018). The inhibition of hepatitis C virus and the human 


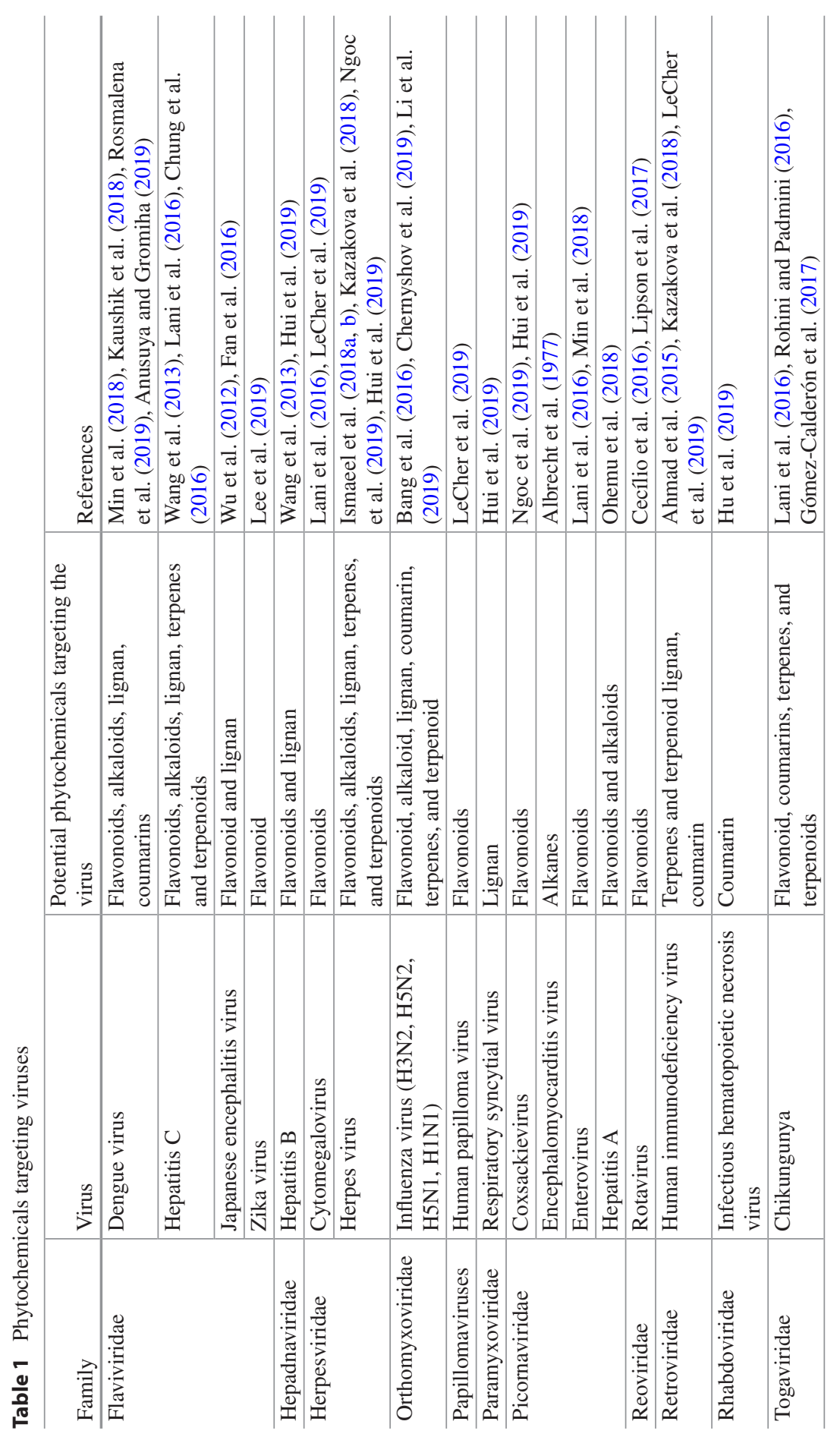




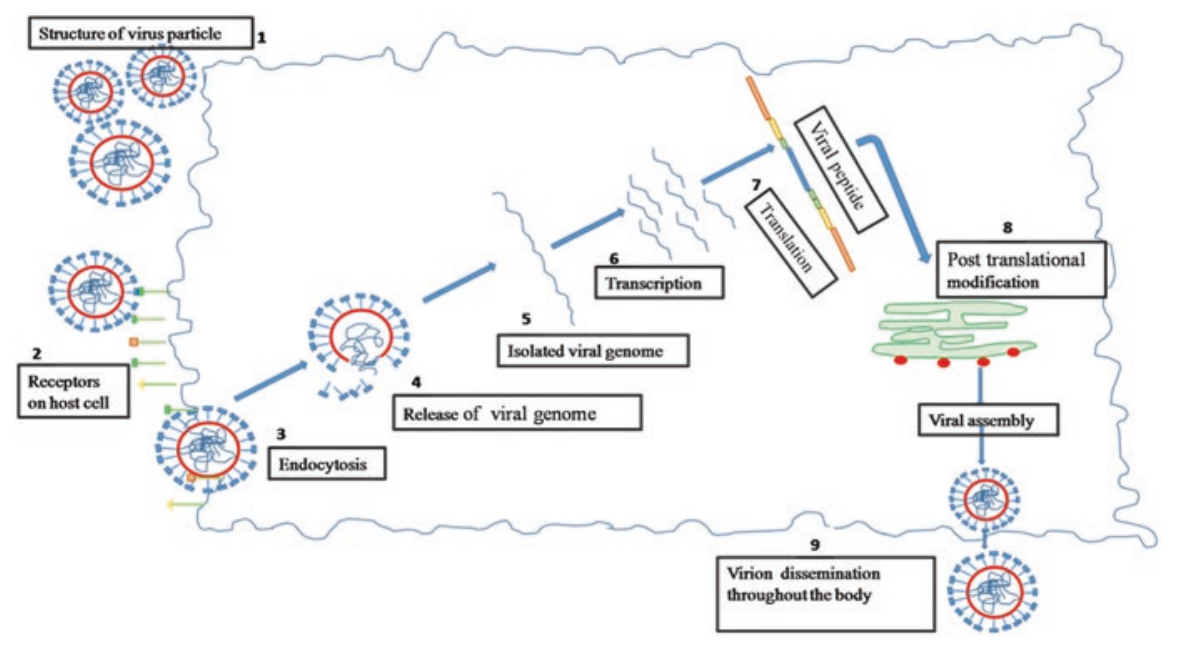

Fig. 2 Different stages of viral infection which can be targeted for the inhibition of virus. (1) Virus is outside the host cell; (2) viral surface proteins get attached to the receptors present in the host cell for the viral entry; (3) virus enters inside the cell by endocytosis; (4) viral genome DNA/RNA is released inside the host cell; (5) viral DNA/RNA gets ready for replication; (6) transcription of viral genome; (7) synthesis of viral proteins; (8) posttranslational modification of proteins in Golgi and endoplasmic reticulum; (9) viral proteins assemble into new virion particle which comes out of the cell

cytomegalovirus (HCMV) infection was done by the activity of quercetagetin (Zakaryan et al. 2017). Moreover, baicalein, quercetagetin, and fisetin were also reported for the inhibition of chikungunya virus by impeding the intracellular viral replication at early stages (Lani et al. 2016). Phenolic acids have shown significant antiviral activity against HSV-1 very significantly (Medini et al. 2016). Similarly, stilbenes have shown antiviral properties against HIV and HCV (Gastaminza et al. 2011; Krawczyk 2019). Fan and co-workers reported luteolin, a nontoxic dietary flavonoid with antiviral activity against Japanese encephalitis virus (JEV). Luteolin belongs to the flavone group of flavonoids and is present in chamomile tea, perilla leaf, green pepper, and celery. The virucidal activity of luteolin was observed in A549 cell lines infected with JEV, and reported that luteolin inhibits the viral replication at the post entry of virus. Luteolin did not inhibit the replication at the time of viral entry (Fan et al. 2016). More recently, a group of researchers have identified pinocembrin having anti-Zika activity. They screened a library containing flavonoids against Zika virus. They analyzed cell viability and viral titers and finally identified pinocembrin (present in honey, tea, and red wine) as an anti-Zika compound. It was observed that the pinocembrin strongly inhibited the Zika virus infection in JEG-3infected cells, and also revealed that it inhibits the viral replication at post entry stages inside the cell (Lee et al. 2019) Likewise, LeCher et al. (2019) have identified the potential phytochemical that is effective against herpes B virus. They have reported genistein, a flavonoid present in Fabaceae family and in soy-based foods. Due to the lack of permanent treatment of herpes B virus, the researchers also 
checked the synergistic effects of genistein with the already available antivirals (acyclovir and ganciclovir) to develop the effective treatment. They have reported the antiviral activity of genistein against herpes B virus, and also revealed that it targets the virus after the viral replication stage. Moreover, its combination with the acyclovir and ganciclovir proved to be effective with the reduction of effective dose (LeCher et al. 2019). Similarly, genistein has been reported to possess antiviral activity against HSV-1, cytomegalovirus, and bovine herpesvirus-1, SV40, human papilloma virus, porcine reproductive and respiratory syndrome virus, African swine fever virus, and HIV (LeCher et al. 2019). Anti-simian rotavirus SA-11 activity of the ethanolic extracts was reported from the leaves of medicinal plant (Myracrodruon urundeuva), found in Brazil (Cecílio et al. 2016). Further, they have investigated the crude extracts to analyze the activity of pure concentrated bioactive compounds and did the evaluation of the virucidal activity against rotavirus SA-11. They have fractioned five compounds from the leaves using TLC and HPLC and checked their anti-rotavirus activity. They have identified that the flavonoid-enriched fraction showed the strongest anti-rotavirus activity (Cecílio et al. 2016). More recently, Iloghalu et al. (2019) researched on the plant extracts to identify the effective antiviral against noroviruses, which has yet no treatment and control. They worked on the phytochemicals extracted from seeds and calyces of Zanthoxylum armatum and Hibiscus sabdariffa to identify the antiviral activity. Also, they selected myricetin, quercetin, kaempferol, and luteolin phenolic compounds and observed viral reduction activity by using norovirusinfected RAW 264.7 cell lines. According to them, quercetin was able to considerably reduce the viral titer, and hence suggested that it can be used in controlling the human norovirus infections (Iloghaluet al. 2019). In a study, 500 compounds in flavonoid library were screened for antiviral activities, and finally selected as the top leading flavonoids (ST077124 and ST024734) and elucidated their antiviral activity against human enterovirus A71 (HEVA71) infection. These leads proved to be effective at the noncytotoxic concentration of $50 \mu \mathrm{M}$ and significantly diminished the viral titers. The compound ST077124 inhibits the human enteroviruses, but another identified compound ST024734 showed the antiviral activity for the infection caused by human enteroviruses, as well as for dengue virus. Both of the compounds hindered the transcription and translation machinery of the virus, and the researchers suggested that these compounds could be the potential inhibitors of HEVA71 (Min et al. 2018). A group of investigators have demonstrated the antiviral activities of Ficus cunninghamii. This plant has been found to contain several flavonoids, such as quercetin-3- $O-\alpha$-D-arabinopyranoside, quercetin-3- $O-\beta-\mathrm{D}-$ galactopyranoside, kaempferol-3- $O$ - $\beta$-D-galactopyranoside, and kaempferol-3- $O$ - $\alpha$ D-arabinopyranoside. They studied the radical scavenging activity and reported the importance of hydroxyl group $(-\mathrm{OH})$ for the activity of flavonoids. The presence of more number of $-\mathrm{OH}$ group enhanced the antioxidant activity of flavonoids. They identified and reported that the flavonoid from $F$. cunninghamii has mild inhibitory effect against hepatitis A virus (Orabi and Orabi 2016). A comparative study on the antiviral activity of flavonoids (EGCG, ECG, quercetin, daidzein, fisetin, baicalein, kaempferol, biochanin A, theaflavin, and digallate) against murine norovirus (MNV) and feline calicivirus (FCV) was carried out by Seo et al. (2016). These flavonoids 
were earlier reported to have an antiviral activity against RNA viruses (Sithisarn et al. 2013; Seo et al. 2016). The results of Seo et al.'s (2016) study concluded that the antiviral activity against MNV and FCV of these flavonoids was found to be in the following order: quercetin $<$ daidzein $<$ fisetin $<$ EGCG and ECG $<$ quercetin $<$ daidzein $<$ kaempferol, respectively. FCV viral titer was significantly reduced by the activity of kaempferol and daidzein at $200 \mathrm{mM}$ concentration level. Moreover, the MNV viral titer was reduced by daidzein and quercetin, when used at the concentration of 50 and $100 \mathrm{mM}$, respectively (Seo et al. 2016). In another study by Bang et al. (2016), the aerial parts of Salvia plebeia $\mathrm{R}$. Br were analyzed for antiviral activity against influenza A (H1N1) neuraminidase. Two of the flavonoids showed antiviral efficacy against H1N1 virus by inhibiting the replication cycle. These flavonoids were found to be potential inhibitors of H1N1 neuraminidase and thus inhibited the growth of the virus (Bang et al. 2016). More recently, the anti-dengue activity of plants found in Indonesia (Myristica fatua, Cymbopogon citratus, and Acorus calamus) was observed by Rosmalena et al. (2019). They have performed in silico as well as in vitro experiments to elucidate the antiviral activity against dengue virus serotype 2 (DENV-2). Although the solvent extracts of all the plants showed the inhibitory effect, the highest inhibition was recorded for the methanolic extracts of $M$. fatua. Hence, they suggested the plant for further exploration to make use of it in the herbal formulations in the treatment of dengue virus (Rosmalena et al. 2019). Moreover, by using in silico studies, Anusuya and co-workers have reported that some of the phytocompounds, such as 5-hydroxy-3,3',4',6,7,8-hexamethylflavone, 4',5,6,7-tetramethylflavone, and 7'-methylamentoflavone, possess the potential of inhibiting dengue virus (Anusuya and Gromiha 2019).

\subsection{Alkaloids as Antiviral Agents}

Alkaloids, a type of secondary metabolite of plants consist of the presence of nitrogen atom in its ring structure. Alkaloids are generally present in the higher plants and comprise of various biological activities like anticancer, antibacterial, antiviral, and antiasthma (Shi et al. 2014). It has been reported that about 43 alkaloids exhibit activity against the influenza virus (Moradi et al. 2018). The antiviral activity against influenza virus by the alkaloids can be due to induction of interferons of the immune system. Some of the alkaloids enhance the activity of macrophages, hence phagocytose to destroy the virus. Alkaloids inhibit the influenza viral infection at different stages of replication. Some of them either inhibit the synthesis of viral proteins or hinder at the other stages of replication (Moradi et al. 2018). In a study by Zhang et al. (2013), it is reported that homonojirimycin (HNJ), an alkaloid extracted from Commelina communis, exhibits a strong inhibitory activity against influenza viral infection. They also carried out in vivo studies, in which the mice infected with the H1N1 showed a good survival rate, when administered with HNJ by developing good immune response against influenza (Zhang et al. 2013). Dendrobine, an alkaloid present in the plant root of Dendrobium nobile, has been analyzed by Li et al. (2017) for its antiviral activity. They reported the antiviral property of dendrobine 
against influenza A viruses. Their studies revealed that dendrobium failed to inhibit the virus during the viral entry, but reduced the viral titer during viral replication. Dendrobine has the ability to bind the nucleoprotein of virus, restraining the viral replication, and hence restricts its export. Moreover, the synergistic effects of dendrobine and zanamivir (a medication used to treat and prevent influenza) were shown to significantly inhibit the influenza A virus replication (Li et al. 2017). More recently, several synthetic compounds were synthesized, including alkaloid analogues, and investigated for their influenza virus inhibition activity (Chernyshov et al. 2019). According to their study results, these compounds successfully inhibited the viral infection and exhibited the antiviral activity against various influenza A virus subtypes (H1N1, H3N2, and H5N2). Wu et al. (2012) extracted alkaloids from the marine-derived fungus Dichotomomyces cejpii F31-1, and elucidated the antiviral activity for the inhibition of dengue virus (Wu et al. 2012). Moreover, Kaushik et al. (2018) reported alkaloids from the plants like Castanospermum australe, Houttuynia cordata, Myrtopsis corymbosa, and Uncaria tomentosa to possess antiviral activity against dengue virus (Kaushik et al. 2018). The preliminary screening of phytochemicals in Phaleria macrocarpa plant showed the presence of alkaloids along with several other phytocompounds. These plant extracts were shown to exhibit nontoxicity to Vero cells, but showed strong antiviral properties against HSV (Ismaeel et al. 2018a, b). Likewise, the methanol extract of Ziziphus jujube plant was shown to have eight cyclopeptide alkaloids. Out of which, three alkaloids showed inhibitory effects against porcine epidemic diarrhea virus (PEDV) using the cytotoxicity assay and cytopathic effect inhibition assay (Kang et al. 2015). Enantia chlorantha (Oliver), a traditional medicinal plant, has been in use in Nigeria for curing malaria fever, caused by Plasmodium spp. This plant has been found to have antiviral activity against hepatitis A, B, C, and D. The alkaloids, such as berberine present in the stem bark of this plant have been assessed by Ohemu et al. (2018) against Newcastle disease virus, and the results showed that alkaloids exhibited toxic effects to the viruses.

\subsection{Terpenes and Terpenoids as Antiviral Agents}

Terpenes consist of five carbon isoprene units with simple hydrocarbons, and belong to the biggest category of secondary metabolites. On the other hand, terpenoids are just the modified forms of terpenes with various functional groups at different positions. Terpenoids, also called as isoprenoids are natural compounds present in plants and have a significant role in pharmaceuticals, therapeutics, and herbal treatments. Terpenoids like diterpenoids, sesquiterpenoids, and triterpenoids have wide variety of application in the area of medicine (Jaeger and Cuny 2016; Perveen and Al-Taweel 2018).

Kazakova et al. (2018) studied the antiviral activity of betulin and dihydroquinopimaric acid derivatives against influenza A virus (H7N1), HSV type 1, nonenveloped RNA virus (ECHO 6), and HIV type 1. The modification at C3 and C28 of betulic acid showed the antiviral activity against HSV-1 and HIV-1. Moreover, 
the modifications at the $\mathrm{C} 4$ position of dihydroquinopimaric acid enhanced the antiH7N1 activity. Due to the lack of cost-effective treatment and the nonavailability of vaccines for $\mathrm{HCV}$, researchers have moved towards the prospective phytochemicalbased therapy, which could be more economical and effective. It has been reported that saikoponins, such as SSa, SSb2, SSc, and SSd isolated from the Bupleurum kaoi root, inhibited the infection of hepatitis C virus (HCV) (Lin et al. 2015). It was reported that saikoponins targeted the viral cycle at their very early steps like viral entry/fusion and not the later phase like transcription and translation of viral cycle. SSb2 was the most effective alkaloid, which significantly inhibited the HCV infection (Lin et al. 2015). The activity of Phyllanthus urinaria plant extract against the HCV early entry was observed by Chung et al. (2016). According to their study, the presence of loliolide, a monoterpene hampered the viral attachment to the host membrane, and thus inhibited its entry. Corlay et al. (2014) analyzed the ethanolic extract from the leaves of Croton mauritianus plant and identified the presence of diterpenes, such as 12-O-decanoylphorbol-13-acetate and 12-O-decanoyl-7hydroperoxy-phorbol-5-ene-13-acetate along with loliolide, vomifoliol, dehydrovomifoliol, annuionone $\mathrm{D}$, and bluemol C. Among these phytoconstituents, 12-O-decanoylphorbol 13-acetate and 12-O-decanoyl-7-hydroperoxy-phorbol-5ene-13-acetate showed significant anti-chikungunya activity (Corlay et al. 2014). In a study to evaluate the potential antiviral activity of Aglaia sp. (family, Meliaceae) (Esimone et al. 2010), the presence of terpenes was identified, which could inhibit HIV-1 by creating a cytotoxic environment and resisting the proliferation of the virus. The terpenes also showed the inhibition of several other viruses, such as retroviruses, including simian immunodeficiency virus and murine leukemic virus. The 3, 4-secodammarane triterpenoid was observed to inhibit cell cycle between $\mathrm{S}$ and $\mathrm{G} 2 / \mathrm{M}$ phase, and thus inhibiting the viral replication and dissemination. Terpenes present in the methanolic extract of Marrubium vulgare were studied for their antiviral activity against HSV-1 through plaque reduction assay (Fayyad et al. 2014). They reported that terpenes could disrupt the attachment of HSV to the cell membrane and interfere in the replication of HSV-1 virus. Likewise, terpenes (oleanolic terpenoids) extracted from the Camellia japonica flowers were analyzed by Yang et al. (2015) for their antiviral activity against PEDV. These compounds suppressed the viral replication by restraining the proper structural formation and inhibited genes coding for GP2 spike, GP5membrane protein, and GP6 nucleocapsid (Yang et al. 2015).

\subsection{Lignan as Antiviral Agents}

Lignans are the phenolic secondary metabolites of plants. Lignans are observed to be antihepatotoxic, anti-inflammatory, and antidepressant. Furthermore, many lignans have been found to be antiviral against HIV and influenza (Hazra and Chattopadhyay 2016; Salehi et al. 2018). A lignin bisphenol, namely honokiol, was identified from Magnolia tree by Fang et al. (2015), and the tree parts are routinely used in the Chinese medicine. The treatment of honokiol to dengue virus strains 
revealed that it could inhibit the synthesis of dsRNA, and interfere in the replication process. The nonstructural proteins, particularly ns 1 and ns 3 , and the intermediate proteins formed during replication were observed to be suppressed by honokiol. The phytochemical studies also revealed that it may affect the endocytic entry of dengue virus, and hence reduce the number of viral particles in the cytoplasm (Fang et al. 2015). A lignan, 3-hydroxy caruilignan C (3-HCL-C), was extracted from the stems of Swietenia macrophylla, and it was found to be effective against chronic hepatitis $\mathrm{C}$ virus (HCV) (Wu et al. 2012). Moreover, the antiviral activity of 3 -HCL-C in combination with interferon- $\alpha$ (IFN- $\alpha$ ), an HCV NS5B polymerase inhibitor (2'-C-methylcytidine; NM-107), or telaprevir (an HCV NS3/4A protease inhibitor) reduced the viral infection significantly. This lignin inhibited the virus at both translation and transcriptional phases. Several other studies have demonstrated the similar activity of 3-HCL-C against HIV-1, hepatitis B, and Japanese encephalitis virus (Wu et al. 2012). A prominent presence of bombasinol, a lignan, is observed in many plants belonging the Bombacaceae family. Upon researching, it was found that this compound had the inhibitory activity against hepatitis B virus (Wang et al. 2013). Furthermore, Pilkington et al. (2018) isolated phytochemicals from the seeds of Silybum marianum and elucidated their antiviral activities against HCV. More recently, Rhinacanthus nasutus plant was evaluated for its use to cure fungal and herpes virus infections. Lignans, isolated from the roots of this plant, demonstrated antiviral activities. The compounds were studied and reported to have antiviral activity against PR8 influenza virus strain, Coxsackie virus, and human rhinovirus 1B virus (Ngoc et al. 2019). A Chinese herb, Radix isatidis has been used for treating several viral diseases, such as influenza virus, HSV, respiratory syncytial virus (RSV), mumps virus, coxsackie virus, and hepatitis B virus. Hui et al. (2019) reported the significant antiviral activity of lignans isolated from this plant. The mechanism hypothesized was that the lignans present in the plant can target adsorption and replication of RSV (Hui et al. 2019). Similarly, lignan glycosides isolated from the fruit of Forsythia suspense were established to possess anti-influenza A (H5N1) activity as revealed by in vitro studies (Li et al. 2019).

\subsection{Coumarins as Antiviral Agents}

Coumarins belong to the benzopyrones family of phytochemicals and were initially found in the plant Dipteryx odorata. These phytochemicals are in medicinal uses, since a long time in many forms of the traditional medicines across the globe (Matos et al. 2015; Bahadori et al. 2016). As reported by Bahadori and co-workers, Simaroubaceae family members have been observed to contain coumarin as a significant phytochemical, and this phytochemical is demonstrated to be biologically active in inhibiting HIV (Bahadori et al. 2016). In another experiment, Mammea americana and Tabernaemontana cymosa were evaluated for their phytochemicals and antiviral activities. M. americana was reported with two types of coumarin compounds (i.e., 34SK001 and 34SK002) obtained after column chromatography and has antiviral property. 
The experiments done by the group of scientist included various strategies, including inhibition assays for dengue as well as chikungunya virus. According to them, almost $100 \%$ inhibition was obtained in vitro by these two coumarins for dengue and chikungunya virus (Gomez-Calderón et al. 2017). Moreover, the medicinal plants aiding the protection against or treatment of dengue and chikungunya virus were tested for the presence of coumarins by Rohini and Padmini (2016). According to them, hexane extract of Andrographis paniculata contained coumarins. Additionally, ethyl acetate extract of Santalum album was shown to have small quantities of coumarins, whereas ethanolic extract showed a slight presence of coumarin in plants A. paniculata, Trichosanthes dioica, Chrysopogon zizanioides, and S. album. As these medicinal plants and their preparations are effective in inhibiting the viral growth, especially due to the occurrence of coumarins, they are commonly used in the treatment of dengue and chikungunya viruses (Rohini and Padmini 2016). An experiment was performed to understand the phytochemical analysis of medicinal plant, Morinda citrifolia, which has been known to exhibit antiviral properties. The bark extracts of the plant were researched for phytochemicals, and the extracted compounds were analyzed by nuclear magnetic resonance spectroscopy to identify the presence of coumarins (Wang et al. 2016). They also predicted that a very significant amount of coumarins in the extract could be involved in the inhibition of H1N1 virus (Wang et al. 2013).

Recently, Hu et al. (2019) designed 24 coumarin derivatives and observed for their activity against infectious hematopoietic necrosis virus (IHNV). Among all of them, only one coumarin (C4) significantly suppressed IHNV infection by inhibiting apoptosis and causing cellular damages. Hence, it could be the potential lead for the development of anti-IHNV vaccine/drug (Hu et al. 2019).

\section{$3 \quad$ Patents on Phytochemicals as Antivirals}

The World Intellectual Property Organization Patent Application (WIPO), with a patent application number of WO2017069661A1 assigned to a limited liability company, claims the antiviral activity of pyrimidyl-di(diazaspiro-alkanes) against herpes virus, HIV, papillomavirus, and hepatitis virus. The US patents US9491193B2 and US 9481630 assigned to Korea Research Institute of Bioscience claim the phorbol-type diterpene compound and ingenane-type diterpene compound, respectively, to show antiviral activity by inhibiting viral replication. Likewise, WO20091589A1, another patent assigned to Instytut Medycyny Doswiadczalnej I Klinicznej PAN, claims the preparations of Viburnum opulus fruit in the prevention and therapy of HSV infections. This preparation claims the use of active ingredients in ointments or creams for external use as well as an active ingredient of pills for oral administration. Another patent, US20170333390A1, assigned to Commission on Higher Education, Chiang Mai University, claims xanthones in combination with sesamin possess anti-inflammatory, anti-cytokine storm, and antiviral activity (against antiinfluenza). The patented phytochemicals are listed in Table 2. 


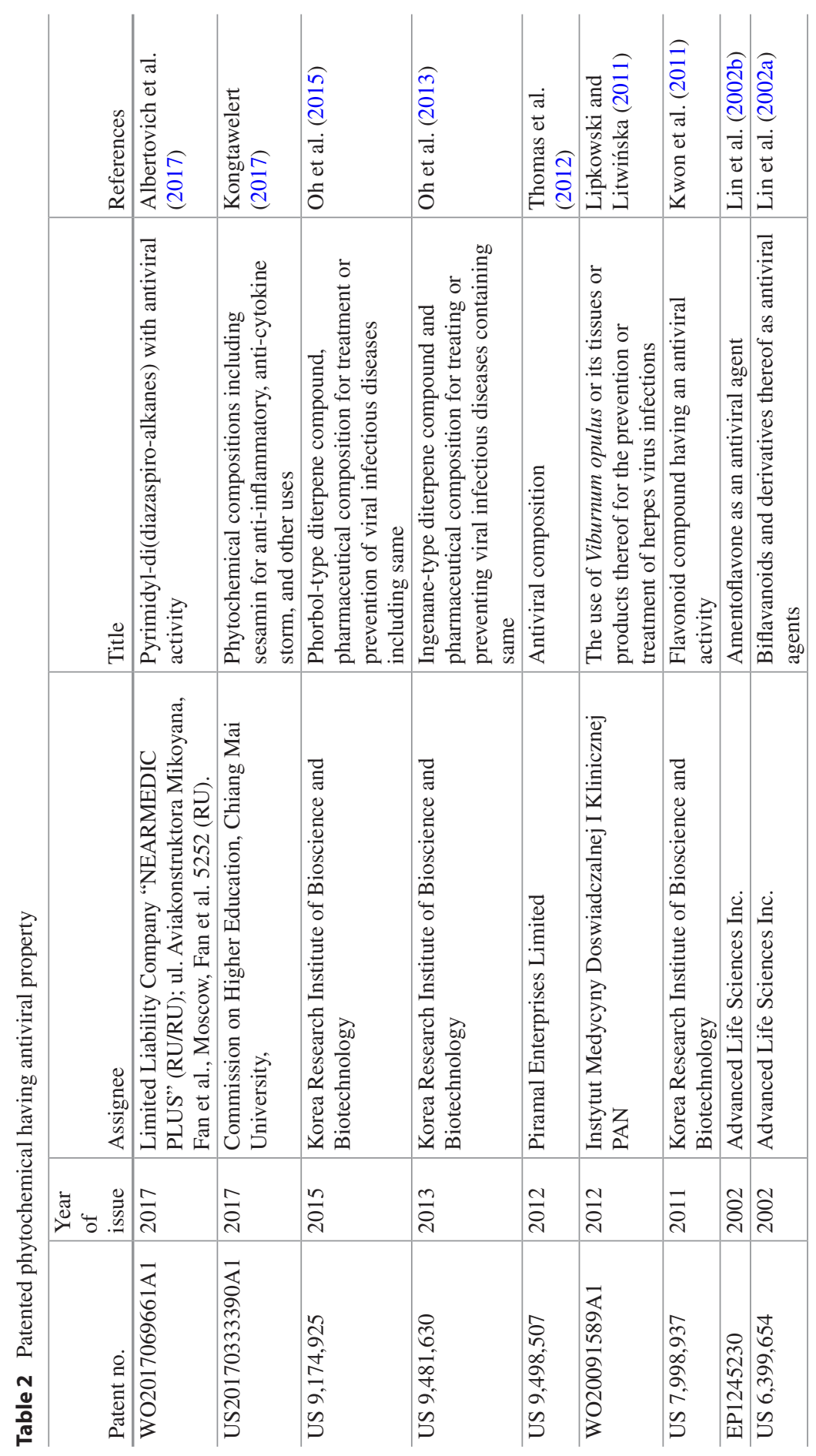




\section{$4 \quad$ Conclusions and Future Perspectives}

Traditional plants have been continuously used in the field of medicine for the treatment of various infections. Therapies based on natural products (phytochemicals) for human health are associated with less toxicity and minimal side effects. Thus, the researchers are focusing to elucidate the new plant-based compounds for the treatment of many diseases. Different plant secondary metabolites have been studied and used for various human-based treatments because of antioxidant, anticancerous, antibacterial, and antiviral properties. Several in silico and in vitro studies have revealed the promising use of photochemicals for the treatment of viral infections. Among all the phytochemicals, flavonoids have been widely exploited and studied for the treatment of several viral diseases. Furthermore, some of the flavonoids exhibited good antiviral activity against influenza, dengue, chikungunya, and many more viruses and can be a potential candidate which can be processed further to the development of antivirals. Other phytochemicals like terpenoids and alkaloids also showed effective activity against viral diseases. Moreover, the combination of phytochemicals with the different compounds either with any synthetic compound or any drug can be also a new, potential approach to find the good antiviral therapies. Along with this, the dose of phytochemicals and the mechanism behind it to inhibit viral infections needs to be further determined which is very essential for the development of effective and potential antiviral drug.

Antiviral therapies for the life-threatening viral diseases are generally expensive and have adverse side effects. Even some of the viral diseases do not have any antiviral treatments like chikungunya virus and HIV. In the realm of the therapeutics, there is an urgent need of effective, safe, and inexpensive antiviral therapies/drugs/ inhibitors with minimal side effects to the mankind. Therefore, the approach using the phytochemical could be the better option in the development of antivirals. Synergistic studies employing phytochemicals in combination with either already FDA-approved drugs or inhibitors could be explored in the future for better and long-term efficacy of antiviral. Moreover, repurposing of already reported phytochemical as an inhibitor for viral diseases could be done in search of potential antivirals. Phytochemicals having antiviral activity can be nanoencapsulated for better delivery, prolonged action, and enhanced bioavailability. Moreover, excessive research on different biodiversity-rich regions could be explored to get more potent phytochemicals and metabolites as antiviral agents.

\section{References}

Ahmad A, Kaleem M, Ahmed Z, Shafiq H (2015) Therapeutic potential of flavonoids and their mechanism of action against microbial and viral infections-a review. Food Res Int 77:221-235

Akram M, Tahir IM, Shah SM, Mahmood Z, Altaf A, Ahmad K, Munir N, Daniyal M, Nasir S, Mehboob H (2018) Antiviral potential of medicinal plants against HIV, HSV, influenza, hepatitis, and coxsackievirus: a systematic review. Phytother Res 32(5):811-822 
Albrecht WL, Fleming RW, Horgan SW, Mayer GD (1977) Bis-basic-substituted polycyclic aromatic compounds. A new class of antiviral agents. 8. Bis-basic derivatives of carbazole, dibenzofuran, and dibenzothiophene. J Med Chem 20(3):364-371

Albertovich MV, Georgievich NV, Nikolaevich BR, Alexandrovna NE (2017) Pyrimidyldi(diazaspiro-alkanes) with antiviral activity. WO2017069661. https://patentscope.wipo.int/ search/en/detail.jsf?docId=WO2017069661. Accessed 12 Sept 2019

Anusuya S, Gromiha MM (2019) Structural basis of flavonoids as dengue polymerase inhibitors: insights from QSAR and docking studies. J Biomol Struct Dyn 37(1):104-115

Bahadori MB, Dinparast L, Zengin G (2016) The genus Heracleum: a comprehensive review on its phytochemistry, pharmacology, and ethnobotanical values as a useful herb. Compr Rev Food Sci F 15(6):1018-1039

Bang S, Ha TK, Lee C, Li W, Oh WK, Shim SH (2016) Antiviral activities of compounds from aerial parts of Salvia plebeia R. Br. J Ethnopharmacol 192:398-405

Biswas D, Nandy S, Mukherjee A, Pandey DK, Dey A (2019) Moringa oleifera Lam and derived phytochemicals as promising antiviral agents: a review. S Afr J Bot. (in press). https://doi. org/10.1016/j.sajb.2019.07.049

Carletti G, Nervo G, Cattivelli L (2014) Flavonoids and melanins: a common strategy across two kingdoms. Int J Biol Sci 10(10):1159

Cecílio AB, Oliveira PD, Caldas S, Campana PR, Francisco FL, Duarte MG, Mendonça LD, Almeida VL (2016) Antiviral activity of Myracrodruon urundeuva against rotavirus. Rev Bras Farm 26(2):197-202

Chernyshov VV, Yarovaya OI, Fadeev DS, Gatilov YV, Esaulkova YL, Muryleva AS, Sinegubova KO, Zarubaev VV, Salakhutdinov NF (2019) Single-stage synthesis of heterocyclic alkaloidlike compounds from (+)-camphoric acid and their antiviral activity. Mol Divers. https://doi. org/10.1007/s11030-019-09932-9

Chung CY, Liu CH, Burnouf T, Wang GH, Chang SP, Jassey A, Tai CJ, Tai CJ, Huang CJ, Richardson CD, Yen MH (2016) Activity-based and fraction-guided analysis of Phyllanthus urinaria identifies loliolide as a potent inhibitor of hepatitis C virus entry. Antiviral Res 130:58-68

Corlay N, Delang L, Girard-Valenciennes E, Neyts J, Clerc P, Smadja J, Guéritte F, Leyssen P, Litaudon M (2014) Tigliane diterpenes from Croton mauritianus as inhibitors of chikungunya virus replication. Fitoterapia 97:87-91

Esimone CO, Eck G, Nworu CS, Hoffmann D, Überla K, Proksch P (2010) Dammarenolic acid, a secodammarane triterpenoid from Aglaia sp. shows potent anti-retroviral activity in vitro. Phytomedicine 17(7):540-547

Fan W, Qian S, Qian P, Li X (2016) Antiviral activity of luteolin against Japanese encephalitis virus. Virus Res 220:112-116

Fang CY, Chen SJ, Wu HN, Ping YH, Lin CY, Shiuan D, Chen CL, Lee YR, Huang KJ (2015) Honokiol, a lignan biphenol derived from the magnolia tree, inhibits dengue virus type 2 infection. Viruses 7(9):4894-4910

Fayyad AG, Ibrahim N, Yaakob WA (2014) Phytochemical screening and antiviral activity of Marrubium vulgare. Malays J Microbiol 10(2):106-111

Gastaminza P, Pitram SM, Dreux M, Krasnova LB, Whitten-Bauer C, Dong J, Chung J, Fokin VV, Sharpless KB, Chisari FV (2011) Antiviral stilbene 1, 2-diamines prevent initiation of hepatitis $\mathrm{C}$ virus RNA replication at the outset of infection. J Virol 85(11):5513-5523

Gómez-Calderón C, Mesa-Castro C, Robledo S, Gómez S, Bolivar-Avila S, Diaz-Castillo F, Martínez-Gutierrez M (2017) Antiviral effect of compounds derived from the seeds of Mammea americana and Tabernaemontana cymosa on dengue and chikungunya virus infections. BMC Complement Altern Med 17(1):57

Hazra S, Chattopadhyay S (2016) An overview of lignans with special reference to podophyllotoxin, a cytotoxic lignan. Chem Biol Lett 3(1):1-8

Helenius A (2018) Virus entry: looking back and moving forward. J Mol Biol 430(13):1853-1862

Hu Y, Chen W, Shen Y, Zhu B, Wang GX (2019) Synthesis and antiviral activity of coumarin derivatives against infectious hematopoietic necrosis virus. Bioorg Med Chem Lett 29(14):1749-1755 
Hui QX, HE LW, Ying YD, Zhang S (2019) Extraction of total lignans from Radix isatidis and its ant-RSV virus effect. Clin J Pharmacol Pharmacother 1(1):1005

Idris F, Muharram SH, Diah S (2016) Glycosylation of dengue virus glycoproteins and their interactions with carbohydrate receptors: possible targets for antiviral therapy. Arch Virol 161(7):1751-1760

Iloghalu U, Holmes B, Khatiwada J, Williams LL (2019) Selected plant extracts show antiviral effects against murine norovirus surrogate. Adv Microbiol 9(4):372

Irwin KK, Renzette N, Kowalik TF, Jensen JD (2016) Antiviral drug resistance as an adaptive process. Virus Evol 2(1):vew014

Ismaeel M, Dyari HR, Nor NS, Yaacob WA, Ibrahim N (2018a) Anti-human herpesvirus type-1 activity of Phaleria macrocarpa fruits methanol extract and fractions. Malays Appl Biol 47(5):31-40

Ismaeel MYY, Dyari HRE, Yaacob WA, Ibrahim N (2018b) In vitro antiviral activity of aqueous extract of Phaleria macrocarpa fruit against herpes simplex virus type 1. AIP Conf Proc 1940(1). https://doi.org/10.1063/1.5027991

Jacob A, Thomas J (2019) Therapeutic potential of dietary flavonoids against viral-borne infections: a review. Drug Invent Today 11(2):469-479.

Jaeger R, Cuny E (2016) Terpenoids with special pharmacological significance: a review. Nat Prod Commun 11(9):1373-1390. 1934578X1601100946

Kang KB, Ming G, Kim GJ, Choi H, Oh WK, Sung SH (2015) Jubanines F-J, cyclopeptide alkaloids from the roots of Ziziphus jujuba. Phytochemistry 119:90-95

Kapoor R, Sharma B, Kanwar SS (2017) Antiviral phytochemicals: an overview. Biochem Physiol 6(2):7

Kaushik S, Kaushik S, Sharma V, Yadav JP (2018) Antiviral and therapeutic uses of medicinal plants and their derivatives against dengue viruses. Pharmacogn Rev 12(24):177

Kazakova OB, Smirnova IE, Baltina LA, Boreko EI, Savinova OV, Pokrovskii AG (2018) Antiviral activity of acyl derivatives of betulin and betulinic and dihydroquinopimaric acids. Russ $\mathbf{J}$ Bioorgan Chem 44(6):740-744

Kongtawelert P (2017) Phytochemical compositions including sesamin for anti-inflammatory, anti-cytokine storm, and other uses. United States Patent application US 14/561,928. https:// patents.google.com/patent/US20150094285A1/en

Krawczyk H (2019) The stilbene derivatives, nucleosides, and nucleosides modified by stilbene derivatives. Bioorg Chem. 103073

Kumar S, Pandey AK (2013) Chemistry and biological activities of flavonoids: an overview. Sci World J 2013:162750

Kwon DH, Choi WJ, Lee CH, Kim JH, Kim MB (2011) Flavonoid compound having an antiviral activity. United States Patent US 7,998,937. https://patents.google.com/patent/ WO2007069823A1

Lani R, Hassandarvish P, Shu MH, Phoon WH, Chu JJ, Higgs S, Vanlandingham D, Bakar SA, Zandi K (2016) Antiviral activity of selected flavonoids against Chikungunya virus. Antiviral Res 133:50-61

LeCher JC, Diep N, Krug PW, Hilliard JK (2019) Genistein has antiviral activity against herpes B virus and acts synergistically with antiviral treatments to reduce effective dose. Viruses 11(6):499

Lee LJ, Loe MW, Lee RC, Chu JJ (2019) Antiviral activity of pinocembrin against Zika virus replication. Antiviral Res 167:13-24

Li R, Liu T, Liu M, Chen F, Liu S, Yang J (2017) Anti-influenza A virus activity of dendrobine and its mechanism of action. J Agric Food Chem 65(18):3665-3674

Li C, Wei Q, Zou ZH, Sun CZ, Wang Q, Zhao G, Yan XJ, Yu TY, Gan CL (2019) A lignan and a lignan derivative from the fruit of Forsythia suspensa. Phytochem Lett 32:115-118

Lillehoj H, Liu Y, Calsamiglia S, Fernandez-Miyakawa ME, Chi F, Cravens RL, Oh S, Gay CG (2018) Phytochemicals as antibiotic alternatives to promote growth and enhance host health. Vet Res 49(1):76 
Lin YM, Zembower DE, Flavin MT, Schure R, Zhao GX (2002a) Biflavanoids and derivatives thereof as antiviral agents. United States Patent US 6,399,654. https://patents.google.com/ patent/EP0833631A1

Lin Y, Schure R, Zhao GX, Flavin MT, Zembower DE (2002b) Amentoflavone as an antiviral agent. US Patent request EP1245230. https://patents.google.com/patent/EP1245230A2/no

Lin LT, Chung CY, Hsu WC, Chang SP, Hung TC, Shields J, Russell RS, Lin CC, Li CF, Yen MH, Tyrrell DL (2015) Saikosaponin b2 is a naturally occurring terpenoid that efficiently inhibits hepatitis C virus entry. J Hepatol 62(3):541-548

Lipkowski A, Litwińska B (2011) The use of viburnum opulus or its tissues or products thereof for the prevention or treatment of herpes virus infections. WO2012091589A1. https://patents. google.com/patent/WO2012091589A1/da

Lipson SM, Karalis G, Karthikeyan L, Ozen FS, Gordon RE, Ponnala S, Bao J, Samarrai W, Wolfe E (2017) Mechanism of anti-rotavirus synergistic activity by epigallocatechin gallate and a proanthocyanidin-containing nutraceutical. Food Environ Virol 9(4):434-443

Matos MJ, Santana L, Uriarte E, Abreu OA, Molina E, Yordi EG (2015) Coumarins-an important class of phytochemicals. In: Rao AV, Rao LG (eds) Phytochemicals-isolation, characterisation and role in human health, IntechOpen, pp 113-140

Medini F, Megdiche W, Mshvildadze V, Pichette A, Legault J, St-Gelais A, Ksouri R (2016) Antiviral-guided fractionation and isolation of phenolic compounds from Limonium densiflorum hydroalcoholic extract. CR CHIM 19(6):726-732

Min N, Leong PT, RCH L, Khuan JSE, Chu JJH (2018) A flavonoid compound library screen revealed potent antiviral activity of plant-derived flavonoids on human enterovirus A71 replication. Antiviral Res 150:60-68

Moradi MT, Karimi A, Lorigooini Z (2018) Alkaloids as the natural anti-influenza virus agents: a systematic review. Toxin Rev 37(1):11-18

Ngoc TM, Phuong NT, Khoi NM, Park S, Kwak HJ, Nhiem NX, Trang BT, Tai BH, Song JH, Ko HJ, Kim SH (2019) A new naphthoquinone analogue and antiviral constituents from the root of Rhinacanthus nasutus. Nat Prod Res 33(3):360-366

Oh SR, Kim JW, Lee HK, Khiev P, Kim DY, Kim JH, Song JS, Ahn KS (2013) Ingenane-type diterpene compound, and pharmaceutical composition for treating or preventing viral infectious diseases containing same. United States Patent US 9,481,630. https://patents.google.com/ patent/US9481630/it

Oh SR, Kim JW, Pei YH, Lee HK, Kang HB, Kim DY, Ahn KS (2015) Phorbol type diterpene compound, pharmaceutical composition for treatment or prevention of viral infectious diseases including same. United States Patent US 9,174,925. https://patents.google.com/patent/ EP2792666A2

Ohemu TL, Agunu A, Chollom SC, Okwori VA, Dalen DG, Olotu PN (2018) Preliminary phytochemical screening and antiviral potential of methanol stem bark extract of Enantia chlorantha Oliver (Annonaceae) and Boswellia dalzielii Hutch (Burseraceae) against Newcastle disease in Ovo. Eur J Med Plants 10:1-8

Oliveira AF, Teixeira RR, Oliveira AS, Souza AP, Silva ML, Paula SO (2017) Potential antivirals: natural products targeting replication enzymes of dengue and chikungunya viruses. Molecules 22(3):505

Orabi MA, Orabi EA (2016) Antiviral and antioxidant activities of flavonoids of Ficus virens: experimental and theoretical investigations. J Pharmacogn Phytochem 5(3):120-128

Perera C, Efferth T (2012) Antiviral medicinal herbs and phytochemicals. J Pharmacogn 3(1):45-48

Perveen S, Al-Taweel A (2018) Introductory chapter: terpenes and terpenoids. In: Terpenes and Terpenoids. IntechOpen, London

Pilkington LI, Wagoner J, Kline T, Polyak SJ, Barker D (2018) 1, 4-benzodioxane lignans: an efficient, asymmetric synthesis of flavonolignans and study of neolignan cytotoxicity and antiviral profiles. J Nat Prod 81:2630-2637

Rex RS, Nadar MS, Selvakumar PM (2018) Phytochemicals as a potential source for antimalaria, antioxidant and wound-healing: a review. MOJ Biorg Org Chem 2(2):61-70 
Rohini MV, Padmini E (2016) Preliminary phytochemical screening of selected medicinal plants of polyherbal formulation. J Pharmacogn Phytochem 5(5):277

Rosmalena R, Elya B, Dewi BE, Fithriyah F, Desti H, Angelina M, Hanafi M, Lotulung PD, Prasasty VD, Seto D (2019) The antiviral effect of indonesian medicinal plant extracts against dengue virus in vitro and in silico. Pathogens 8(2):85

Salehi B, Kumar N, Şener B, Sharifi-Rad M, Kılıç M, Mahady G, Vlaisavljevic S, Iriti M, Kobarfard F, Setzer W, Ayatollahi S (2018) Medicinal plants used in the treatment of human immunodeficiency virus. Int J Mol Sci 19(5):1459

Seo DJ, Jeon SB, Oh H, Lee BH, Lee SY, Oh SH, Jung JY, Choi C (2016) Comparison of the antiviral activity of flavonoids against murine norovirus and feline calicivirus. Food control 60:25-30

Shi QI, Hui SU, Zhang AH, Hong-Ying XU, Guang-Li YA, Ying HA, Xi-Jun WA (2014) Natural alkaloids: basic aspects, biological roles, and future perspectives. Chin J Nat Med 12(6):401-406

Sithisarn P, Michaelis M, Schubert-Zsilavecz M, Cinatl J Jr (2013) Differential antiviral and antiinflammatory mechanisms of the flavonoids biochanin A and baicalein in H5N1 influenza A virus-infected cells. Antiviral Res 97(1):41-48

Subudhi B, Chattopadhyay S, Mishra P, Kumar A (2018) Current strategies for inhibition of chikungunya infection. Viruses 10(5):235

Thomas BM, Saklani A, Kapoor N, Enose AA, Sawant SN, Kaushik R, Bhowmick R, Malani A (2012) Antiviral composition. United States Patent US 9,498,507. https://patentimages.storage. googleapis.com/fe/6a/33/77757ac5b44134/WO2012110932A1.pdf

Wang GK, Lin BB, Rao R, Zhu K, Qin XY, Xie GY, Qin MJ (2013) A new lignan with anti-HBV activity from the roots of Bombax ceiba. Nat Prod Res 27(15):1348-1352

Wang J, Qin X, Chen Z, Ju Z, He W, Tan Y, Zhou X, Tu Z, Lu F, Liu Y (2016) Two new anthraquinones with antiviral activities from the barks of Morinda citrifolia (Noni). Phytochem Lett $15: 13-15$

Wu SF, Lin CK, Chuang YS, Chang FR, Tseng CK, Wu YC, Lee JC (2012) Anti-hepatitis C virus activity of 3-hydroxy caruilignan $\mathrm{C}$ from Swietenia macrophylla stems. J Viral Hepat 19(5):364-370

Yang JL, Ha TK, Dhodary B, Pyo E, Nguyen NH, Cho H, Kim E, Oh WK (2015) Oleanane triterpenes from the flowers of Camellia japonica inhibit porcine epidemic diarrhea virus (PEDV) replication. J Med Chem 58(3):1268-1280

Younas M, Hano C, Giglioli-Guivarc'h N, Abbasi BH (2018) Mechanistic evaluation of phytochemicals in breast cancer remedy: current understanding and future perspectives. RSC Adv 8(52):29714-29744

Zakaryan H, Arabyan E, Oo A, Zandi K (2017) Flavonoids: promising natural compounds against viral infections. Arch Virol 162(9):2539-2551

Zhang G, Zhang B, Zhang X, Bing F (2013) Homonojirimycin, an alkaloid from dayflower inhibits the growth of influenza A virus in vitro. Acta Virol 57(1):85-86 